\title{
Characterization of Components of Partial Resistance, Rps 2, and Root Resistance to Phytophthora sojae in Soybean
}

\author{
Santiago Mideros, Mizuho Nita, and Anne E. Dorrance
}

Department of Plant Pathology, The Ohio State University, Wooster 44691.

Current address of M. Nita: Department of Plant Pathology, Pennsylvania State University, University Park 16803.

Accepted for publication 22 November 2006.

\begin{abstract}
Mideros, S., Nita, M., and Dorrance, A. E. 2007. Characterization of components of partial resistance, Rps2, and root resistance to Phytophthora sojae in soybean. Phytopathology 97:655-662.

Phytophthora root and stem rot of soybeans caused by Phytophthora sojae is a serious limitation to soybean production in the United States. Partial resistance to $P$. sojae in soybeans is effective against all the races of the pathogen and is a form of incomplete resistance in which the level of colonization of the root is reduced following inoculation. Other forms of incomplete resistance include the single dominant gene Rps 2 and Ripley's root resistance, which are both race-specific. To differentiate partial resistance from the other types of incomplete resistance, the

resistant genotype Conrad, while the root-resistant genotype also had significantly smaller lesion lengths. However, the high levels of partial resistance in Jack were indistinguishable from Rps 2 in L76-1988, based on the evaluation of these components. Root resistance in Ripley and Rps2 in L76-1988 had similar responses for all components measured in this study. Partial resistance expressed in Conrad, Williams, Jack, and General was comprised of various components that interact for defense against $P$. sojae in the roots, and different levels of each component were found in each of the genotypes. However, forms of incomplete resistance expressed via single genes in Ripley and Rps2 in L76-1988, could not be distinguished from high levels of partial resistance based on lesion length, oospore production, and infection frequency.
\end{abstract} components lesion length, numbers of oospores, and infection frequency were measured in eight soybean genotypes inoculated with two $P$. sojae isolates. The Rps 2 and root-resistant genotypes had significantly lower oospore production and infection frequency compared with the partially
Additional keywords: Glycine max, host resistance, incomplete resistance, partial resistance.
The oomycete Phytophthora sojae Kaufmann \& Gerdemann (Phytophthora megasperma Drechs. f. sp. glycinea Kuan \& Erwin) causes Phytophthora root and stem rot of soybean (Glycine max L. Merr.) and is a limitation for soybean production around the world (56-58). Early in the season, this pathogen also causes pre- and post-emergence damping-off (18), and with heavy rains in midseason, susceptible cultivars yellow and wilt as the lateral roots are colonized. Plants which develop these stem rot symptoms usually wilt and die (16,34).

Phytophthora root and stem rot is predominantly managed through genetic host resistance via deployment of single resistance genes (Rps), but partial resistance to $P$. sojae also exists (34). Currently, 14 Rps genes have been reported at 8 loci, with a series of alleles at two of the loci $(6,17,34)$. This management strategy has favored shifts in the pathogen population toward individuals adapted to specific $R p s$ genes, thus increasing the number of races and the virulence composition among isolates $(18,34)$. Currently, the combination of single resistance genes and partial resistance is recommended in order to avoid the boom and bust cycle that results from deployment of single resistance genes, but also to minimize yield losses when adaptation to Rps genes does occur $(1,18)$.

There are different criteria used to classify plant resistance to pathogens (20). This study addresses phenotypic aspects of soybean resistance to $P$. sojae. Therefore, the reactions produced by Rps genes (except Rps2) will be considered as complete resistance because they do not allow pathogen development beyond

Corresponding author: A. E. Dorrance; E-mail address: dorrance.1@osu.edu

doi:10.1094/PHYTO-97-5-0655

(c) 2007 The American Phytopathological Society early stages of infection. Heitefuss (20) defined complete resistance as the absence of "development of the pathogen beyond early stages of infection that totally prevents its propagation." Conversely, Heitefuss (20) defined incomplete resistance as "limited development of the pathogen including some propagation and that may reduce spread of a disease in a host population." These definitions of complete and incomplete resistance were based on the terminology of Parlevliet (30). For this study, the effect of the soybean Rps 2 gene, "root resistance" and partial resistance, where limited colonization of the host occurs along with limited propagation of $P$. sojae, will be termed incomplete resistance (20,30). All of the reported Rps genes except Rps 2 completely arrest the growth of $P$. sojae through the hypersensitive response (HR) in the hypocotyl (18). The mechanisms of resistance associated with Rps $1 \mathrm{a}$ and $R p s 1 \mathrm{~b}$ genes include rapid cell death with necrosis beginning 4 hours after inoculation (hai), and cell wall appositions that encase the haustoria as soon as 4 hai (15). Rps gene resistance is characterized by a more rapid necrosis affecting fewer cells when compared with susceptible interactions $(15,40,41,54)$. The presence of $R p s$ genes in soybeans is usually determined using the hypocotyl inoculation technique. Plants are rated as resistant or susceptible depending on whether or not a lesion develops following inoculation of 7-day-old soybean seedlings with $P$. sojae (11).

Partial resistance is a form of incomplete resistance in the $P$. sojae-soybean system that results in reduced colonization by the pathogen. Partial resistance can be divided into specific components that limit the infection process $(30,47)$. Several components of partial resistance such as infection frequency, latent period, spore production, incubation period, and others have been identified in other host-pathogen systems $(10,12,19,30,32,52,59)$. Partial resistance to $P$. sojae in soybean is expressed and inherited 
quantitatively, effective against all the races of the pathogen, and has been shown to be polygenic $(18,34,53)$. The exact number of genes involved in partial resistance is still unknown, although two quantitative trait loci (QTL) have been identified in 'Conrad' (7), and 4 QTL in the line V71-370 (36). In the field, genotypes with high levels of partial resistance have fewer plants that develop stem rot and have more consistent yields in the presence of the pathogen than those that do not have partial resistance $(45,46)$. Partial resistance to $P$. sojae has also been referred to as ratereducing resistance, field resistance, and tolerance in the soybean literature (18).

Another type of incomplete resistance in soybean is conferred by Rps 2 . This dominant single resistance gene was first reported more than 30 years ago in the soybean line D54-2437, derived from the genotype CNS (23). Interestingly, the genotype CNS and some of its derived lines have complete resistance in the field. A unique feature of the Rps 2 gene is that the resistance is expressed completely only in the roots and has an intermediate reaction in the hypocotyls, whereas other soybean $\mathrm{R}$ genes are all expressed in the hypocotyl (23). An intermediate reaction is one in which only $50 \%$ of hypocotyls will develop lesions following inoculation. The reaction of the Rps 2 has been previously described as a type of root resistance (34).

Root resistance has also been reported in soybeans that do not have Rps2. Soybean genotypes Ripley, York, and Ware have a susceptible reaction to hypocotyl inoculation and a resistant response when inoculated on the roots, but with different race specificity than Rps2 (42,43). McBlain et al. (28) studied the inheritance of resistance to $P$. sojae in Ripley in a cross with the susceptible genotype Harper. In the population, resistance was inherited quantitatively with a heritability value of 0.54 . In addition, they concluded that the genotype Ripley also has a race-specific root resistance similar to the resistance conferred by the $R p s 2$, but with different race specificity (28).

The previously described studies in soybeans have highlighted the difficulty of distinguishing between high levels of partial resistance (non-race-specific) and incomplete forms of resistance due to a single gene such as Rps $2(28,42)$. Incomplete resistance conferred by single genes with different race specificities has also been reported in other host pathogen systems. Incomplete $\mathrm{R}$ genes $(R 2, R 4, R 10$, and $R 11)$ of potato against $P$. infestans can be mistaken for partial resistance and can only be differentiated using the appropriate isolates of the pathogen (9). In barley it has been shown that different genes for resistance to Blumeria graminis f. sp. hodei PM-R genes control different infection phenotypes called fast, intermediate, and slow-acting genes $(24,25)$. Fast-acting genes do not allow fungal penetration through the process of epidermal cell death or other mechanisms. Intermediate acting genes limit hyphal development, and cell death was delayed until 24 to 72 hai. Finally, slow-acting PM-R genes allow robust hyphal growth for 72 hai, followed by cell death $(24,25)$.

The use of parental lines with known specific components has been proposed as a way to improve the efforts of breeding for potato partial resistance to $P$. infestans $(10,12)$. Unfortunately, there are limited studies of components of partial resistance in the soybean- $P$. sojae system and for the expression of resistance in roots in general. Lesion length was shown to be effective to model disease development, and to differentiate between genotypes with various levels of partial resistance (51), but it is not known if other components can be identified in soybean roots and what the contribution of each component is to the overall response to infection.

The hypothesis is that partial resistance, root resistance, and Rps2-mediated incomplete resistance, as they are expressed in soybeans, are all different mechanisms of incomplete resistance that can be differentiated by examining several components of partial resistance. Therefore the objectives of this study were to: (i) identify and determine the relationship of components of soy- bean partial resistance to $P$. sojae; (ii) determine if lesion length, infection frequency, and oospore production are different among the incomplete resistance types (Rps2, root resistance, and partial resistance); and (iii) determine which component(s) most accurately differentiate(s) among these different types of incomplete resistance. For this study, eight soybean genotypes with various levels of partial resistance and different types of incomplete resistance were inoculated with a complex $P$. sojae pathotype (soybean genotypes with Rps genes are susceptible) to examine partial resistance (non-race-specific) and with a simple $P$. sojae pathotype (soybeans with $R p s 7$ are susceptible) to differentiate among types of incomplete resistance.

\section{MATERIALS AND METHODS}

$P$. sojae isolates and inoculum. Two isolates of $P$. sojae from the collection of the soybean pathology laboratory at The Ohio State University were used: a simple pathotype OHR1 (vir. 7) and a complex pathotype 1.S.1.1 (vir. 1a, 1b, 1k, 2, 3a, 3b, 3c, 4, 5, 6, $7,8)$. To characterize the pathotypes of the isolates, the following differentials were used in this study: 'Williams' (universal susceptible); 'Harlon' (Rps1a), 'Harosoy 13XX' (Rps1b), 'Williams 79' (Rps1c); PI103091 (Rps1d); 'Williams 82' (Rps1k); L76-1988 (Rps2); L83-570 (Rps3); PRX 146-36 (Rps3b); PRX 145-48 (Rps3c); L85-2352 (Rps4); L85-3059 (Rps5); 'Harosoy 62XX' (Rps6) and 'Harosoy' (Rps7) (11). The pathogenicity of the isolates was maintained via inoculation and re-isolation from 'Sloan' using standard methodologies (33). Long-term storage of isolates was in $10 \%$ sterile glycerol in cryovials in liquid nitrogen (44). Oospores from approximately a 3- to 4-week-old culture grown on V8-juice agar were first transferred to cryovials and placed overnight at $-80^{\circ} \mathrm{C}$ prior to liquid nitrogen as described by Tooley (44). For recovery, cryovials were submerged in a water bath at $25^{\circ} \mathrm{C}$ for $10 \mathrm{~min}$ and the entire contents were poured onto a plate of V8-juice agar or lima-bean agar.

Soybean seedlings were inoculated with either zoospores or a mycelial slurry of $P$. sojae. Zoospores were produced by transferring five plugs $(6 \mathrm{~mm})$ onto non-clarified V8-juice agar plates. Four days later plates were flooded with $15 \mathrm{ml}$ of sterile deionized water (pH 6 to 7) for approximately 14 to 18 hours. Level of $\mathrm{pH}$ in water has been shown to be critical; at $\mathrm{pH}$ levels lower than 6.0, zoospores will burst (A. Dorrance et al., unpublished data). Water in plates was then removed and fresh water added every $30 \mathrm{~min}$ for a total of 7 times, with a final incubation for $3 \mathrm{~h}$ at $26^{\circ} \mathrm{C}$ (31). Zoospores were collected and counted with a hemacytometer. The concentration of zoospores was adjusted to $1 \times 10^{4}$ zoospores per $\mathrm{ml}$ of water.

The mycelial slurry was prepared from 7-day-old cultures of $P$. sojae growing on dilute lima-bean agar $(15 \mathrm{~g}$ agar/liter $)$ at $26^{\circ} \mathrm{C}$ (33). The colonized agar was macerated through a $60-\mathrm{ml}$ syringe without a needle. This mycelial slurry was then transferred to a 10 -ml syringe with a needle $(18$-gauge $\times 2.54 \mathrm{~cm})$.

Soybean genotypes. A collection of genotypes consisting of cultivars, breeding lines, and differentials was chosen to represent the different types of resistant reactions: Rps genes, partial resistance, Rps 2 , and root resistance. The genotypes, pedigrees, and resistance to $P$. sojae are listed in Table 1.

Lesion length. The slant board assay was used to assess lesion length $(7,29)$. Briefly, seeds of the eight genotypes were planted in $946 \mathrm{~cm}^{3}$ polystyrene containers (Dart 32TJ32, Mason, MI) with the following layers: (i) an $\sim 2-\mathrm{cm}$ layer of coarse vermiculite (Therm O-Rock \#1A, New Eagle, PA) at the bottom of the containers; (ii) $15 \mathrm{~cm}$ of fine vermiculite (Therm O-Rock \#4, New Eagle, PA); and (iii) 25 seeds, with another $\sim 2 \mathrm{~cm}$ layer of coarse vermiculite. The containers were placed in a growth chamber with temperatures between 22 and $26^{\circ} \mathrm{C}$, and a 14-h photoperiod using both fluorescent and incandescent light bulbs. Seven-day-old seedlings were removed from the containers and the vermiculite 
washed from the roots in running tap water. Eight to ten plants were aligned on a polyester cloth that was placed on top of a thick, 0.5-mm absorbent cotton wicking pad on a plastic tray (27 $\times 35 \mathrm{~cm})$ that had the raised side $(2 \mathrm{~cm})$ of one end removed. With a scalpel, a wound of $5 \mathrm{~mm}$ was scraped on the tap root $2 \mathrm{~cm}$ below the stem/root interface. A $1-\mathrm{cm}^{3}$ of the mycelial slurry of $P$. sojae was then applied over the wound with a syringe. Trays were stacked and bound together with a large rubber band, and placed in 25-liter plastic containers with 2 liters of deionized water in the bottom. Roots were between the polyester cloth and were not in direct contact with water. The plastic containers were maintained for 7 days in a growth chamber with temperatures between 22 and $26^{\circ} \mathrm{C}$, and a 14-h photoperiod using both fluorescent and incandescent light bulbs.

Lesion lengths were measured from the site of inoculation toward the cotyledon on each seedling. Previous reports have shown no significant differences in lesion length for measurements below the inoculation site (49). To clearly assess the presence of the pathogen, roots and hypocotyls were sliced open to expose the root stele. For each genotype, ten plants within a tray were the experimental unit. There were three replicates in each experiment and the experiment was repeated three times. The experimental design was a split plot design where isolate type was the main factor (25-liter plastic container) and genotype was the subfactor.

Number of oospores. Resistance to reproduction of $P$. sojae was measured by counting the number of oospores that formed in a 1-cm section of the root immediately below the inoculation site. These root pieces were collected from the same seedlings assayed for lesion length and were placed in $80 \%$ ethanol (14). The root tissue was fixed by heating in a microwave for $5 \mathrm{~min}$ on the high setting $\left(\sim 100^{\circ} \mathrm{C}\right)$ and then placed on the lab bench at approximately $25^{\circ} \mathrm{C}$ for one hour. Ethanol was poured off and the root sections were rinsed once in deionized water and then placed in commercial bleach $(5.25 \% \mathrm{NaClO})$. Vials containing the root samples were placed in a drying oven for $5 \mathrm{~min}$ at $60^{\circ} \mathrm{C}$. Root samples were then kept at $4{ }^{\circ} \mathrm{C}$ until oospores were counted.

The root pieces of each genotype were placed on a glass slide with water and a cover slip. The mount was pressed to an approximately one- to two-cell depth to ensure that all the oospores could be observed under a compound microscope. Oospores were counted in 1-cm root pieces from four or six plants from each tray. The average for each tray was used for the statistical analysis. There were three replicates within each experiment and the whole experiment was repeated three times. The experimental design was a split plot design where isolate type was the main factor (25-liter plastic container) and genotype was the subfactor.

Infection frequency. A modified slant board assay was used to measure infection frequency. Seeds of the eight soybean genotypes were sown in polystyrene containers with vermiculite as described above. Seven-day-old seedlings were rinsed in running tap water and ten seedlings were aligned on top of a $10 \times 5-\mathrm{cm}$ strip of Parafilm that was placed on the polyester cloth which was on top of a wicking pad. The roots were inoculated by placing a $10-\mu l$ drop of water containing $1 \times 10^{4}$ zoospores per $\mathrm{ml}$ at five positions on the root. The first drop was placed on the interface between the stem and the root, and four more inoculation positions were $2 \mathrm{~cm}$ below each other. Following inoculation the plants were incubated for $20 \mathrm{~min}$ at approximately $25^{\circ} \mathrm{C}$ to favor zoospore encystment and penetration. Plants were covered with the polyester cloth and stacked as in the regular slant board assay in 25-liter plastic containers as described above.

Data for infection frequency was collected 3 days after inoculation by slicing the root and counting the number of water-soaked lesions at each of the five inoculation positions. The number of lesions that developed out of the 50 total inoculation sites was collected for the ten plants on each tray. The infection frequency among the inoculation positions was also determined as the proportion for each position within each tray. Each experiment was in a split-split plot design where isolate was considered as the main factor, genotype as the subfactor, and position of inoculation as the sub-subfactor. There were three replicates in each experiment and the whole experiment was repeated three times.

Data analysis. Homogeneity of variances was tested using Levene's test in Minitab release 14.2 (Minitab Inc., State College, PA). Variance infection frequency data was homogenized using an arcsine square root transformation, and oospore counts and lesion lengths were $\log _{10}$-transformed. Each component of resistance was analyzed with Proc MIXED of SAS V.9.1 (SAS Institute Inc., Cary, NC). Replicates within experiment and repetition of the experiments were considered random factors, while isolates, genotype, and their interactions were considered fixed factors. For factors with significant differences $(P=0.05)$, Tukey-Kramer multiple range test was used for comparisons of least square means (27). Tukey-Kramer multiple range test was chosen for this analysis due to the large number of mean comparisons as well as some missing values $(27,37)$.

The rank of the genotypes for each component of resistance and independent isolate was obtained using Proc RANK in SAS. Spearman correlations were done using Proc CORR in SAS to determine if there were relationships among the components of partial resistance for the eight genotypes inoculated only with the complex pathotype of P. sojae (1.S.1.1), because of the non-racespecific interaction.

\section{RESULTS}

When all eight genotypes and $P$. sojae isolates were compared, they were significantly different $(P<0.0001)$ from each other for all the components of resistance measured in this study (Table 2). The interaction of isolate by host genotype was also significant $P<0.0001)$ for all the components. This significant interaction was expected due to isolate-specific resistance genes to $P$. sojae

TABLE 1. Type of incomplete and Rps gene resistance expressed to simple and complex pathotypes of Phytophthora sojae in soybean genotypes used in this study

\begin{tabular}{|c|c|c|c|c|c|}
\hline \multirow[b]{2}{*}{ Genotype } & \multirow[b]{2}{*}{ Rps gene } & \multirow[b]{2}{*}{ Incomplete resistance } & \multicolumn{2}{|c|}{ Rps gene response to $P$. sojae } & \multirow[b]{2}{*}{ Pedigree; (Literature cited) } \\
\hline & & & $\begin{array}{l}\text { Simple } \\
\text { (OHR1) }\end{array}$ & $\begin{array}{l}\text { Complex } \\
\text { (1.S.1.1) }\end{array}$ & \\
\hline General & $R p s 1 \mathrm{k}$ & High partial resistance & $\mathrm{R}$ & $\mathrm{S}$ & Voris311 × Resnik; (48) \\
\hline Williams & rps & Medium partial resistance & $\mathrm{S}$ & $\mathrm{S}$ & Wayne $\times$ L57-0034 $($ Clark $\times$ Adams $) ;(48,49)$ \\
\hline Conrad & rps & Medium partial resistance & $\mathrm{S}$ & $\mathrm{S}$ & A3127 $\times$ Tri-Valley Charger (Williams in background); $(48,49)$ \\
\hline Ox20-8 & Rpsla & Low partial resistance & $\mathrm{R}$ & $\mathrm{S}$ & M405 × Harosoy $63 ;(8,49)$ \\
\hline
\end{tabular}

${ }^{\mathrm{z}}$ Rps gene, race-specific resistance response of seedlings after inoculation with $P$. sojae using a modified hypocotyl inoculation technique. $\mathrm{R}$ (resistant) $=$ zero to two seedlings developed lesions; I (intermediate) = three to six seedlings developed lesions; and S (susceptible) = seven to eight seedlings developed lesions. The pathotypes of the isolates were OHR1 (vir. 7) and 1.S.1.1 (vir. 1a, 1b, 1k, 2, 3a, 3b, 3c, 4, 5, 6, 7, 8). 
isolate OHR1 in genotypes with Rps1a, Rps1k, Rps2, and root resistance, but these same genotypes are susceptible to the complex isolate 1.S.1.1.

Lesion length. For the $\mathrm{R}$ gene response to the simple pathotype (OHR1), estimated mean lesion sizes were 1.0, 1.6, and $1.6 \mathrm{~mm}$ for General (Rps1k), Ox20-8 (Rps1a), and Ripley (root resistance), respectively (Table 3 ). Lesion size of Rps 2 expressed in L76-1988 (3.1 $\mathrm{mm})$ was significantly larger than General (Rps $1 \mathrm{k})$, but not larger than Ox20-8 (Rps1a). The lesion lengths of Jack were not significantly different from the L76-1988 (Rps2), from Ox20-8 (Rps1a), or from Ripley (root resistance) genotypes, but Jack had significantly larger lesions than did General (Rps $1 \mathrm{k}$ ). Sloan was highly susceptible to both the simple and complex P. sojae pathotypes ( 23.0 and $29.3 \mathrm{~mm}$, respectively).

Lesion size for Jack was significantly smaller $(4.9 \mathrm{~mm})$ for the complex pathotype (1.S.1.1), compared with all but one of the other genotypes, but similar in size $(3.7 \mathrm{~mm})$ to the simple pathotype (OHR1) (Table 3). For the complex pathotype (1.S.1.1) no racespecific responses were measured among any genotypes. Ox20-8 was the most susceptible to the complex pathotype (1.S.1.1), with an average lesion length of $40.7 \mathrm{~mm}$, which was significantly dif- ferent from Conrad, Jack, General, L76-1988 (Rps2), and Ripley. No significant differences in lesion size were found among the responses of Williams, Conrad, General, L76-1988 (Rps2), and Ripley to the complex $P$. sojae pathotype.

When genotypes with non-race-specific response to both the simple and complex pathotypes were compared, the results were mixed (Table 3). Williams and Conrad inoculated with the complex pathotype resulted in significantly larger lesion length $(P \leq 0.05)$, while Sloan and Jack were not significantly different.

Number of oospores. An average of less than one oospore per 1-cm root section developed in genotypes with Rps1a (Ox20-8) and Rps1k (General) following inoculation with the simple $P$. sojae pathotype (Table 3). Few oospores $(<5)$ were found in the genotypes with incomplete race-specific resistance Rps 2 (L76-1988) and root resistance (Ripley). The root-resistant genotype (Ripley) and Jack did not differ from the Rps2 genotype (L76-1988). The remaining three genotypes with rps genes (Sloan, Williams, and Conrad), had significantly more oospores than did genotypes with Rps genes (General, Ox20-8, and L76-1988), as did the root-resistant genotype, Ripley.

TABLE 2. Analysis of variance (ANOVA) ${ }^{\mathrm{w}}$ for three components of resistance to two Phytophthora sojae isolates among eight soybean genotypes, including racespecific and non-race-specific interactions

\begin{tabular}{|c|c|c|c|c|c|c|}
\hline \multirow[b]{2}{*}{ Effect } & \multicolumn{2}{|c|}{ Lesion length ${ }^{\mathrm{x}}$} & \multicolumn{2}{|c|}{ Oospores $/ \mathrm{cm}^{\mathrm{y}}$} & \multicolumn{2}{|c|}{ Infection frequency ${ }^{z}$} \\
\hline & $F$ & $P>F$ & $F$ & $P>F$ & $F$ & $P>F$ \\
\hline Isolate & 439.72 & $<0.0001$ & 395.61 & $<0.0001$ & 107.02 & $<0.0001$ \\
\hline Genotype & 12.96 & $<0.0001$ & 9.70 & 0.0002 & 23.94 & $<0.0001$ \\
\hline Position & -- & -- & -- & - & 19.95 & $<0.0001$ \\
\hline Isolate*position & -- & -- & -- & -- & 1.82 & 0.1236 \\
\hline Genotype*position & -- & -- & -- & -- & 1.99 & 0.0020 \\
\hline
\end{tabular}

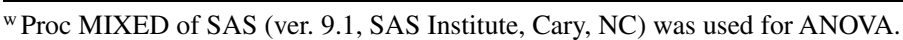

${ }^{\mathrm{x}}$ Lesion length was measured (millimeters) from the top of the inoculation site to the edge of the symptomatic tissue 7 days after inoculation.

${ }^{y}$ Mean number of oospores from four to six 1-cm root pieces collected immediately below the inoculation site 7 days after inoculation.

${ }^{\mathrm{z}}$ Infection frequency was measured as the proportion of successful infections from five inoculation points on the roots of 10 seedlings.

TABLE 3. Estimated means for each component of resistance of eight soybean genotypes inoculated with simple and complex pathotypes of Phytophthora sojae

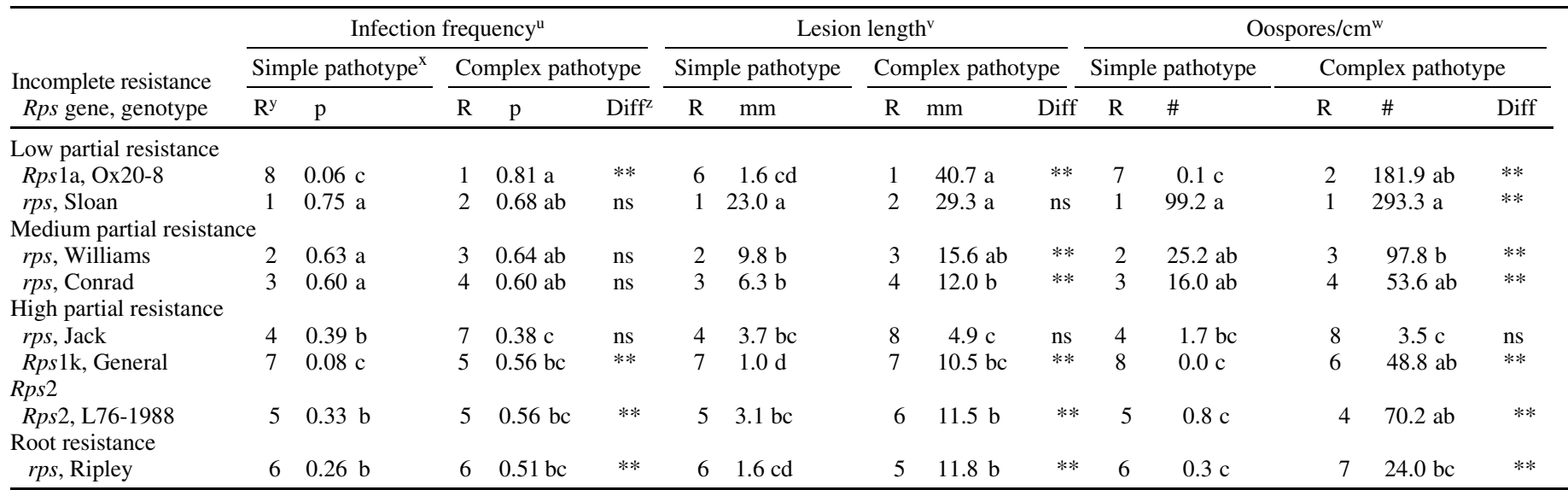

${ }^{\mathrm{u}}$ Infection frequency was measured as the proportion of successful infections of five inoculation points on the roots of 10 seedlings. Ten plants were in trays in a slant board assay. There were three repetitions (trays), and the whole experiment was repeated three times. Proportions of each tray were arcsine square roottransformed prior to analysis. Different letters in the same column indicate a significant difference based on Tukey-Kramer multiple range test.

${ }^{v}$ Lesion length was measured (millimeters) from the top of the inoculation site to the edge of the symptomatic tissue 7 days after inoculation. Ten plants were in trays in a slant board assay. There were three repetitions (trays), and the whole experiment was repeated three times. Data were transformed using log 10 value prior to analysis (PROC MIXED of SAS), and data presented in the table are back-transformed values of expected lesion length based on the least square mean. Different letters in the same column indicate a significant difference based on Tukey-Kramer multiple range test.

${ }^{\mathrm{w}}$ Oospore numbers were determined by counting the total oospores in a 1-cm root piece below the inoculation point on four to six plants 7 days after inoculation. Ten plants were on each tray in a slant board assay. There were three repetitions (trays) and the whole experiment was repeated three times. Data were transformed using $\log 10$ value prior to the analysis (PROC MIXED of SAS), and data presented in the table are back-transformed values of the expected number of oospores based on the least square mean. Different letters in the same column indicate a significant difference based on Tukey-Kramer multiple range test.

${ }^{x}$ The simple pathotype was OHR1 (vir. 7); and the complex pathotype was 1.S.1.1 (vir. 1a, 1b, 1k, 2, 3a, 3b, 3c, 4, 5, 6, 7, 8).

${ }^{\mathrm{y}} \mathrm{R}=$ rank in the column.

${ }^{\mathrm{z}}$ Diff $=$ difference between isolates, based on Tukey-Kramer multiple range test. $* *=$ significant difference, and ns $=$ not significant. 
In the susceptible interaction with the complex $P$. sojae pathotype (1.S.1.1) various groups of genotypes could be distinguished based on the number of oospores (Table 3). The first group consisted of Sloan and Ox20-8, in which the highest numbers of oospores developed. In the second group, large numbers of oospores developed in root sections of Conrad, Williams, General, and L76-1988, although not significantly different from Sloan or from Ripley. Fewer oospores developed in root sections of Ripley, which was significantly different from Sloan. The fewest number of oospores developed in Jack, which was significantly different from all other genotypes except Ripley (root resistance), with an estimated mean of only 3.5 oospores per $1-\mathrm{cm}$ root section.

In a comparison of the genotypes without race-specific resistance, there were significantly more oospores formed in roots inoculated with the isolate with the complex pathotype compared with the simple pathotype, with one exception (Table 3). For the genotype Jack, very few oospores formed.

Infection frequency. In the resistant response to the simple $P$. sojae pathotype (OHR1), the Rps1a (Ox20-8) and the Rps $1 \mathrm{k}$ genotypes (General) had the lowest infection frequencies, with 0.06 and 0.08 , respectively (Table 3 ). These values were significantly lower than all the other genotypes in this study. The Rps 2 genotype (L76-1988) and the root-resistant genotype (Ripley) had infection frequencies of 0.33 and 0.26 , respectively, which was significantly greater than the Rps $1 \mathrm{a}$ and $R p s 1 \mathrm{k}$ genotypes. The $R p s 2$ genotype (L76-1988) infection frequency was not significantly different from that of either the root-resistant genotype (Ripley) or Jack. Sloan had the highest infection frequency (0.75), which was not significantly different from that of Conrad or Williams, which had infection frequencies of 0.60 and 0.63 , respectively.

Ox20-8 had the highest infection frequency when inoculated with the complex pathotype (1.S.1.1) (Table 3). Sloan, Williams, Conrad, General, Ripley, and L76-1988 did not show significantly different infection frequencies. Jack had the lowest level of infection frequency (0.38) against the complex pathotype of $P$. sojae, which was significantly different from Williams and Conrad, which showed medium levels of partial resistance.

Inoculation position on the root affects infection frequency. Significant differences $(P<0.0001)$ in infection frequencies were found among soybean genotypes and inoculation positions for both $P$. sojae isolates (Tables 2 and 4 ). The interaction of genotype by position for both isolates was significant $(P=0.002)$. There were significantly fewer infections for Jack at the stem/root zone compared to positions below this site. Although it was not statistically significant, for all of the genotypes, the most successful infections occurred at positions four and five (Table 4).
Correlation of the components of partial resistance. The correlation of components for partial resistance was evaluated with only the complex P. sojae pathotype (1.S.1.1) for the nonrace-specific response (Table 5). Lesion length was significantly correlated with infection frequency, with a coefficient of correlation of 0.61 (Table 5). Lesion length and the number of oospores were not significantly correlated, nor was infection frequency significantly correlated with the number of oospores.

Rank changes for the components of partial resistance. Based on the smallest lesion size, fewest oospores, and lowest infection frequency, Jack had the highest levels of partial resistance expressed in this study (Table 3 ). The most susceptible genotype, Ox20-8, ranked first for both infection frequency and lesion length with the complex pathotype. Sloan (with low levels of partial resistance) did not differ from Williams and Conrad for infection frequency but Conrad was significantly more resistant than Sloan for lesion length. Ripley was the second most resistant genotype for infection frequency (sixth) and oospore counts (seventh), but ranked fifth for lesion length (Table 3).

\section{DISCUSSION}

In this study, partial resistance was characterized using a complex $P$. sojae isolate that produced a susceptible interaction on all soybean genotypes (18), thus eliminating the race-specific response of Rps1a, Rps $1 \mathrm{k}, R p s 2$, and Ripley's root resistance. Significant differences among the soybean genotypes were found for the three components of soybean partial resistance to $P$. sojae which were evaluated. The susceptible soybean genotype Sloan was similar to genotype Conrad in response to the isolate with the

TABLE 5. Spearman correlation coefficients for lesion length ${ }^{\mathrm{w}}$, oospores $/ \mathrm{cm}^{\mathrm{x}}$, and infection frequency ${ }^{\mathrm{y}}$ in eight soybean genotypes inoculated with a complex isolate of Phytophthora sojae (1.S.1.1)

\begin{tabular}{lcc}
\hline Component & Lesion length & Oospores/cm \\
\hline Infection frequency & $0.61^{\mathrm{z}}$ & 0.14 \\
Lesion length & 1 & 0.30 \\
\hline
\end{tabular}

${ }^{\mathrm{w}}$ Infection frequency was measured as the proportion of successful infection of five inoculation points on the roots of 10 plants 3 days after inoculation.

${ }^{x}$ Lesion length was measured (millimeters) from the top of the inoculation site to the edge of the symptomatic tissue 7 days after inoculation.

y Oospore numbers were determined by counting the total oospores in $1-\mathrm{cm}$ root pieces below the inoculation point on four to six plants 7 days after inoculation.

${ }^{\mathrm{z}} P \leq 0.01$.

TABLE 4. Effect of inoculation position on infection frequency proportion ${ }^{y}$ on the roots of eight soybean genotypes inoculated with two Phytophthora sojae isolates

\begin{tabular}{|c|c|c|c|c|c|c|c|c|}
\hline \multirow[b]{2}{*}{ Position } & \multicolumn{8}{|c|}{ Genotype $^{z}$} \\
\hline & Conrad & General & Jack & L76-1988 & $\mathrm{O} \times 20-8$ & Ripley & Sloan & Williams \\
\hline \multirow[t]{2}{*}{ one } & $0.46 \mathrm{a}$ & $0.21 \mathrm{a}$ & $0.15 \mathrm{a}$ & $0.37 \mathrm{a}$ & $0.34 \mathrm{a}$ & $0.25 \mathrm{a}$ & $0.60 \mathrm{a}$ & $0.50 \mathrm{a}$ \\
\hline & A & $\mathrm{B}$ & B & $\mathrm{AB}$ & $\mathrm{AB}$ & B & A & A \\
\hline \multirow[t]{2}{*}{ two } & $0.62 \mathrm{a}$ & $0.23 \mathrm{a}$ & $0.24 \mathrm{ab}$ & $0.49 \mathrm{a}$ & $0.42 \mathrm{a}$ & $0.29 \mathrm{a}$ & $0.80 \mathrm{a}$ & $0.63 \mathrm{a}$ \\
\hline & $\mathrm{A}$ & $\mathrm{B}$ & B & $\mathrm{AB}$ & $\mathrm{AB}$ & B & A & A \\
\hline \multirow[t]{2}{*}{ three } & $0.65 \mathrm{a}$ & $0.33 \mathrm{a}$ & $0.49 \mathrm{bc}$ & $0.49 \mathrm{a}$ & $0.39 \mathrm{a}$ & $0.44 \mathrm{a}$ & $0.80 \mathrm{a}$ & $0.69 \mathrm{a}$ \\
\hline & $\mathrm{BC}$ & $\mathrm{D}$ & BCD & $\mathrm{BCD}$ & $\mathrm{CD}$ & $\mathrm{BCD}$ & A & $\mathrm{AB}$ \\
\hline \multirow[t]{2}{*}{ four } & $0.63 \mathrm{a}$ & $0.36 \mathrm{a}$ & $0.59 \mathrm{c}$ & $0.42 \mathrm{a}$ & $0.42 \mathrm{a}$ & $0.49 \mathrm{a}$ & $0.70 \mathrm{a}$ & $0.69 \mathrm{a}$ \\
\hline & $\mathrm{AB}$ & B & $\mathrm{AB}$ & B & B & $\mathrm{AB}$ & A & A \\
\hline \multirow[t]{2}{*}{ five } & $0.65 \mathrm{a}$ & $0.39 \mathrm{a}$ & $0.50 \mathrm{c}$ & $0.45 \mathrm{a}$ & $0.42 \mathrm{a}$ & $0.45 \mathrm{a}$ & $0.67 \mathrm{a}$ & $0.70 \mathrm{a}$ \\
\hline & A & A & A & A & A & A & A & A \\
\hline
\end{tabular}

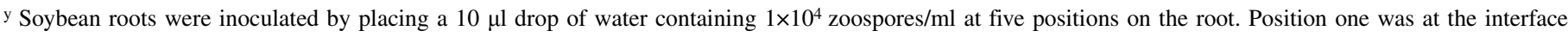
between the stem and the root, and four more positions were $2 \mathrm{~cm}$ below each other. Infection frequency proportions are the means of three experiments with three replicates of 10 plants in each experiment. Data were arcsine $(\sqrt{ } \mathrm{x})$ transformed prior to analysis; presented data are back-transformed (expected infection efficiency based on the least square means).

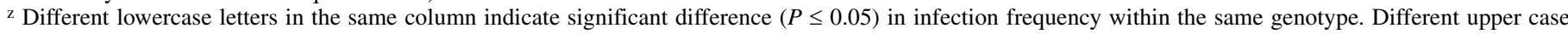
letters below the number in the same row indicate significant difference in infection frequency within the same inoculation position according to Tukey-Kramer multiple range test. 
complex pathotype for infection frequency and for the number of oospores; but it had significantly larger root lesions. Sloan was also similar to the genotype Williams for infection frequency and lesion length but had significantly higher number of oospores. These results suggest that partial resistance expressed in the genotypes Williams and Conrad is composed of more than one factor which affects lesion length and oospore production. These results also suggest that high levels of soybean partial resistance to $P$. sojae can be the result of combinations of various mechanisms of resistance where the different components influence the total level of partial resistance. For example, Jack, which is considered to be a high partial resistance genotype, had the lowest infection frequency, fewer number of oospores, and smallest lesion size.

In addition, low coefficients of correlation were found among the components of partial resistance, but lesion length was significantly correlated with infection frequency. This correlation suggests that studies of partial resistance in the soybean- $P$. sojae system that assay lesion length as a tool to identify partial resistance, will also capture some aspects of infection frequency, but may not capture some aspects of oospore production. Low coefficients of correlation for components of partial resistance and changes in the ranking of genotypes have been reported in many foliar-host pathogen interactions, such as wheat infected with Septoria nodorum (19) or with Microdochium nivale (5), and Solanum species infected with $P$. infestans (10).

An additional finding of this study is that L76-1988, an isoline of the genotype Williams with the Rps 2 gene, was not significantly different from Williams for any of the components of resistance studied with the complex pathotype. This confirms earlier reports that no residual effects were found in the presence of defeated Rps genes (60). These results provide additional evidence that partial resistance in soybeans is not the result of residual effects of Rps genes, whether they confer complete or incomplete resistance, and suggests that partial resistance appears to be a separate mechanism of resistance from the known Rps genes.

Complete and incomplete resistance due to Rps genes was evaluated on the interaction with the simple pathotype that produces a race-specific response by $R p s 1 \mathrm{a}, R p s 1 \mathrm{k}, R p s 2$, and the root resistance genotype Ripley. Expression of Rps genes in soybean following inoculation with $P$. sojae has been reported to produce cell wall appositions and cell death in a hypersensitive response $(15,40)$. In this study, the $\mathrm{R}$ gene response of Rps $1 \mathrm{a}$ and $R p s 1 \mathrm{k}$ genes were expressed to the simple $P$. sojae pathotype and had significantly lower values than those genotypes with medium partial resistance (Conrad and Williams) for all the components of resistance measured. Low infection frequency, very small lesions, and few oospores per root section developed. The presence of oospores in resistant genotypes has been observed by other researchers, and it has been debated whether inoculum builds or is maintained even when resistant soybeans are planted $(2,38)$. If these oospores are viable, this would provide evidence that even effective Rps genes do not completely arrest inoculum production (34), and thus provide $P$. sojae with a strong selection pressure that may, in part, explain the continuous appearance of more complex isolates $(13,21,35)$.

Rps 2 incomplete resistance to the simple $P$. sojae pathotype (OHR1) was expressed as intermediate values for all the components of resistance studied. These values were greater than those measured for the Rps gene response for infection efficiency (Ox20-8, Rps1a; General, Rps1k) and for lesion length (General, $R p s 1 \mathrm{k})$. Previous reports have called the Rps 2 a type of root resistance because it confers complete levels of resistance only in the roots of the plant but not in the hypocotyls $(18,34)$. This study indicated that levels of suppression of disease components measured with the Rps 2 genotype in the root were similar to that with other genotypes with high levels of partial resistance, such as Jack. This type of reaction at the phenotypic level is similar to that described for the slow-acting resistance genes of barley that confer incomplete resistance to Blumeria graminis f. sp. hordei. In that situation the response of barley genes $M l k$ and $M l p$ allows the formation of small colonies with limited sporulation (25). There are also reports of race-specific incomplete resistance genes to oomycetes. For example the genes $R 2, R 4, R 10$, and $R 11$ in potato confer an incomplete type of resistance to $P$. infestans (9). In addition, the $R B$ gene from Solanum bulbocastanum provides an incomplete resistance phenotype in a transformed potato variety that is known to be susceptible (39). The Arabidopsis gene $R P P 1-W s B$ confers only incomplete resistance to Pernospora parasitica even though it is a member of a complex $\mathrm{R}$ gene locus and the other members of the RPPI family confer complete resistance (4). Timing for the onset of the hypersensitive reaction and cell death has been suggested as one of the mechanisms for these intermediate phenotypic responses $(22,24,25,50)$.

The genotype Ripley has race-specific root-resistance to the simple $P$. sojae isolate and produced an intermediate response to all the components of resistance measured, similar to the Rps 2 response. These results are similar to those reported by McBlain et al. (28), in which Ripley developed small, 2-mm lesions. The difficulty encountered in this previous study to detect a major gene in the cross between Ripley and Harper was probably due to the assumption that soybeans with $\mathrm{R}$ genes will rarely produce lesions in these root inoculations (ie., the assumption that $\mathrm{R}$ genes produce an HR, not a susceptible lesion) (28).

Partial resistance expressed in the genotype Conrad to the simple $P$. sojae pathotype had higher infection frequency and more oospores than both the Rps 2 and the root-resistant genotype. However, Jack, which has high levels of partial resistance (26), did not differ from the Rps 2 genotype when inoculated with the simple isolate (OHR1). This emphasizes the difficulty in differentiating between high levels of partial resistance and single genes that confer incomplete resistance.

Differences among inoculation positions on soybean roots have been found previously. Stössel et al. (40) reported that the root/hypocotyl interface is more resistant than hypocotyls of etiolated plants. Their cytological evaluation demonstrated that $P$. sojae did not colonize the root/hypocotyl interface $(40,41)$ and that these differences were attributed to age-related resistance because the root/hypocotyl interface cells were 2 to 3 days older $(40,41,55)$. The results of our study of infection frequency also showed that with most of the genotypes tested, the root/stem interface is more resistant than the lower root region, albeit only the cultivar Jack had significant differences based on TukeyKramer multiple range test. In our study, there was no forced etiolation of any tissue, thus confirming that the root/stem interface is more resistant to infection than other root tissues. Age differences can be a possible source of variation among the results, but in order to prove this, inoculation of the same region of tissue in plants of different age would be required.

In summary, results from this study showed that various components could contribute to produce a partial resistance phenotype for defense against $P$. sojae in soybean roots. However, the high levels of partial resistance in Jack were indistinguishable from the Rps 2 and root resistance reaction for many of these same components. Both the Rps 2 and the root resistance phenotypes reacted similarly to the reaction of barley slow resistance genes to Blumeria graminis f. sp. hordei and to the reaction of potato partial resistance genes to $P$. infestans, in that all produce incomplete types of resistance.

QTL for partial resistance have been associated with lesion length $(7,36)$ in two soybean genotypes. Future studies should evaluate if different QTL may be found that are associated with the remaining components of resistance. However, the methodology to measure infection frequency and the number of oospores at the moment restricts the number of lines that can be phenotyped in any one experiment. Molecular tools which quantify the number of oospores would greatly expedite studies which map QTL associated with resistance to reproduction. 


\section{ACKNOWLEDGMENTS}

We thank J. L. Zambrano, T. Smith, and S. A. Berry for technical assistance; and C. H. Sneller for valuable discussions during the preparation of this study. Salaries and research support were provided by State and Federal Funds appropriated to the Ohio Agricultural Research and Development Center, The Ohio State University, Wooster. This work was supported in part by NSF Plant Genome grant DBI-0211863, and by Ohio's Soybean Producers' check-off dollars through the Ohio Soybean Council.

\section{LITERATURE CITED}

1. Anderson, T. R., and Buzzell, R. I. 1982. Efficacy of metalaxyl in controlling Phytophthora root and stalk rot of soybean cultivars differing in field tolerance. Plant Dis. 66:1144-1145.

2. Beagle-Ristaino, J. E., and Rissler, J. F. 1983. Histopathology of susceptible and resistant soybean roots inoculated with zoospores of Phytophthora megasperma f. sp. glycinea. Phytopathology 73:590-595.

3. Bernard, R. L., Nelson, R. L., and Cremeens, C. R. 1975. Pages 27-57 in: USDA soybean genetic collection: Isoline collection. USDA-ARS, University of Illinois, Urbana.

4. Botella, M. A., Parker, J. E., Frost, L. N., Bittner-Eddy, P. D., Beynon, J. L., Daniels, M. J., Holub, E. B., and Jones, J. D. 1998. Three genes of the Arabidopsis RPP1 complex resistance locus recognize distinct Peronospora parasitica avirulence determinants. Plant Cell 10:18471860.

5. Browne, R. A., Murphy, J. P., Cooke, B. M., Devaney, D., Walsh, E. J., Griffey, C. A., Hancock, J. A., Harrison, S. A., Hart, P., Kolb, F. L., McKendry, A. L., Milus, E. A., Sneller, C., and Van Sanford, D. A. 2005. Evaluation of components of Fusarium head blight resistance in soft red winter wheat germ plasm using a detached leaf assay. Plant Dis. 89:404411.

6. Burnham, K. D., Dorrance, A. E., Francis, D. M., Fioritto, R. J., and St. Martin, S. K. 2003. Rps8, a new locus in soybean for resistance to Phytophthora sojae. Crop Sci. 43:101-105.

7. Burnham, K. D., Dorrance, A. E., Van Toai, T. T., and St. Martin, S. K. 2003. Quantitative trait loci for partial resistance to Phytophthora sojae in soybean. Crop Sci. 43:1610-1617.

8. Buzzell, R. I., and Anderson, T. R. 1982. Plant loss response of soybean cultivars to Phytophthora megasperma f. sp. glycinea under field conditions. Plant Dis. 66:1146-1148.

9. Colon, L. T., Jansen, R. C., and Budding, D. J. 1995. Partial resistance to late blight (Phytophthora infestans) in hybrid progenies of four South American Solanum species crossed with diploid S. tuberosum. Theor. Appl. Genet. 90:691-698.

10. Colon, L. T., Budding, D. J., Keizer, L. C. Paul, and Pieters, M. M. J. 1995. Components of resistance to late blight (Phytophthora infestans) in eight South American Solanum species. Eur. J. Plant Pathol. 101:441-456.

11. Dorrance, A. E., Jia, H., and Abney, T. S. 2004. Evaluation of soybean differentials for their interaction with Phytophthora sojae. Plant Health Progr. Online publication no. 10.1094/PHP-2004-0309-01-RS.

12. Dorrance, A. E., Inglis, D. A., Helgeson, J. P., and Brown, C. R. 2001. Partial resistance to Phytophthora infestans in four Solanum crosses. Amer. J. Potato Res. 78:9-17.

13. Dorrance, A. E., McClure, S. A., and deSilva, A. 2003. Pathogenic diversity of Phytophthora sojae in Ohio soybean fields. Plant Dis. 87:139146.

14. Drenth, A., Janssen, E. M., and Govers, F. 1995. Formation and survival of oospores of Phytophthora infestans under natural conditions. Plant Pathol. 44:86-94.

15. Enkerli, K., Hahn, M. G., and Mims, C. W. 1997. Ultrastructure of compatible and incompatible interactions of soybean roots infected with the plant pathogenic oomycete Phytophthora sojae. Can. J. Bot. 75:14931508 .

16. Erwin, D. C., and Ribeiro, O. K. 1996. Phytophthora Diseases Worldwide. The American Phytopathological Society, St. Paul, MN.

17. Gordon, S. G., St. Martin, S. K., and Dorrance, A. E. 2006. Rps 8 maps to a resistance gene rich region on soybean molecular linkage group. Crop Sci. 46:168-173.

18. Grau, C. R., Dorrance, A. E., Bond, J., and Russin, J. S. 2004. Fungal Diseases. Pages 679-763 in: Soybeans: Improvement, Production, and Uses. 3rd ed. H. R. Boerma and J. E. Specht, eds. Agron. Monogr. 16. Am. Soc. Agron., Crop Sci. Soc. Am., and Soil Sci. Soc. Am., Madison, WI.

19. Griffiths, H. M., and Jones, D. G. 1987. Components of partial resistance as criteria for identifying resistance. Ann. Appl. Biol. 110:603-610.

20. Heitefuss R. 1997. General Principles of Host-Parasite Interactions. Pages 19-29 in: Resistance of Crop Plants Against Fungi. H. Hartleb, R.
Heitefuss, and H. Hoppe, eds. Gustav Fischer Verlag, Jena, Germany.

21. Kaitany, R. C., Hart, L. P., and Safir, G. R. 2001. Virulence composition of Phytophthora sojae in Michigan. Plant Dis. 85:1103-1106.

22. Kamoun, S., Huitema, E., and Vleeshouwers, V. G. 1999. Resistance to oomycetes: A general role for the hypersensitive response? Trends Plant Sci. 4:196-200.

23. Kilen, T. C., Hartwig, E. E., and Keeling, B. L. 1974. Inheritance of a second major gene for resistance to Phytophthora rot in soybeans. Crop Sci. 14:260-262.

24. Kruger, W. M., Carver, T. L. W., and Zeyen, R. J. 2002. Effects of inhibiting phenolic biosynthesis on penetration resistance of barley isolines containing seven powdery mildew resistance genes or alleles. Physiol. Mol. Plant P. 61:41-51.

25. Kruger, W. M., Szabo, L. J., and Zeyen, R. J. 2003. Transcription of the defense response genes chitinase IIb, PAL and peroxidase is induced by the barley powdery mildew fungus and is only indirectly modulated by $\mathrm{R}$ genes. Physiol. Mol. Plant. P. 63:167-178.

26. Kyle, D. E., and Nickell, C. D. 1998. Genetic analysis of tolerance to Phytophthora sojae in the soybean cultivar Jack. Soybean Genetics Newsl. 25:124-125.

27. Littell, R. C., Milliken, G. A., Stroup, W. W., Wolfinger, R. D., and Schabenberber, O. 2006. SAS for Mixed Models. 2nd ed. SAS Inst. Inc., Cary, NC.

28. McBlain, B. A., Zimmerly, M. M., Schmitthenner, A. F., and Hacker, J. K. 1991. Tolerance to Phytophthora rot in soybean: I. Studies of the cross 'Ripley' × 'Harper'. Crop Sci. 31:1405-1411.

29. Olah, A. F., and Schmitthenner, A. F. 1985. A growth chamber test for measuring Phytophthora root rot tolerance in soybean seedlings. Phytopathology 75:546-548.

30. Parlevliet, J. E. 1979. Components of resistance that reduce the rate of epidemic development. Annu. Rev. Phytopathol. 17:203-222.

31. Qutob, D., Hraber, P. T., Sobral, B. W., and Gijzen, M. 2000. Comparative analysis of expressed sequences in Phytophthora sojae. Plant Physiol. 123:243-254.

32. Rashid, K. Y. 1991. Evaluation of components of partial resistance to rust in flax. Can. J. Plant Pathol. 13:212-217.

33. Schmitthenner, A. F., and Bhat, R. G. 1994. Useful methods for studying Phytophthora in the laboratory. OARDC, The Ohio State University, Wooster.

34. Schmitthenner, A. F. 1985. Problems and progress in control of Phytophthora root rot of soybean. Plant Dis. 69:362-368.

35. Schmitthenner, A. F., Hobe, M., and Bhat, R. G. 1994. Phytophthora sojae races in Ohio over a 10-year interval. Plant Dis. 78:269-276.

36. Skoneczka, J., Godwin, M., Mideros, S., Zambrano, J. L., Tucker, D. M., Dorrance, A. E., Tyler, B., and Saghai Maroof, M. A. 2006. Mapping quantitative trait loci for partial resistance to Phytophthora sojae in soybean. Plant and Animal Genomes Conf. 14th. Online publication P439.

37. Sheskin, D. J. 2003. Handbook of Parametric and Nonparametric Statistical Procedures. 3rd ed. CRC Press, Boca Raton, FL.

38. Slusher, R. L., and Sinclair, J. B. 1973. Development of Phytophthora megasperma var. sojae in soybean roots. Phytopathology 63:1168-1171.

39. Song, J., Bradeen, J. M., Naess, S. K., Raasch, J. A., Wielgus, S. M., Haberlach, G. T., Liu, J., Kuang, H., Austin-Phillips, S., Buell, C. R., Helgeson, J. P., and Jiang, J. 2003. Gene $R B$ cloned from Solanum bulbocastanum confers broad spectrum resistance to potato late blight. Proc. Natl. Acad. Sci. USA 100:9128-9133.

40. Stössel, P., Lazarovits, G., and Ward, W. B. 1981. Electron microscope study of race-specific and age-related resistant and susceptible reactions of soybeans to Phytophthora megasperma var. sojae. Phytopathology 71:617-623.

41. Stössel, P., Lazarovits, G., and Ward, W. B. 1980. Penetration and growth of compatible and incompatible races of Phytophthora megasperma var. sojae in soybean hypocotyl tissues differing in age. Can. J. Bot. 58:25942601.

42. Thomison, P. R., Thomas, C. A., and Kenworthy, W. J. 1991. Tolerant and root-resistant soybean cultivars: Reactions to Phytophthora rot in inoculum-layer tests. Crop Sci. 31:73-75.

43. Thomison, P. R., Thomas, C. A., Kenworthy, W. J., and McIntosh, M. S. 1988. Evidence of pathogen specificity in tolerance of soybean cultivars to Phytophthora rot. Crop Sci. 28:714-715.

44. Tooley, P. W. 1988. Use of uncontrolled freezing for liquid nitrogen storage of Phytophthora species. Plant Dis. 72:680-682.

45. Tooley, P. W., and Grau, C. R. 1984. Field characterization of ratereducing resistance to Phytophthora megasperma f. sp. glycinea in soybean. Phytopathology 74:1201-1208.

46. Tooley, P. W., and Grau, C. R. 1984. The relationship between ratereducing resistance to Phytophthora megasperma f. sp. glycinea and yield in soybean. Phytopathology 74:1209-1216.

47. Umaerus, V. 1970. Studies on field resistance to Phytophthora infestans 5. 
Mechanisms of resistance and applications to potato breeding. $\mathrm{Z}$. Pflanzenzüchtg 63:1-23.

48. USDA, ARS, and National Genetic Resources Program. 2005. Germplasm Resources Information Network (GRIN). Online database, Nat. Germplasm Resources Laboratory.

49. Vega-Sanchez, M. E., Redinbaugh, M. G., Costanzo, S., and Dorrance, A. E. 2005. Spatial and temporal expression analysis of defense-related genes in soybean cultivars with different levels of partial resistance to Phytophthora sojae. Physiol. Mol. Plant P. 66:175-182.

50. Vleeshouwers, V. G., van Dooijeweert, W., Govers, F., Kamoun, S., and Colon, L. T. 2000. The hypersensitive response is associated with host and nonhost resistance to Phytophthora infestans. Planta 210:853-864.

51. Wagner, R. E., Carmer, S. G., and Wilkinson, H. T. 1993. Evaluation and modeling of rate-reducing resistance of soybean seedlings to Phytophthora sojae. Phytopathology 83:187-192.

52. Waliyar, F., Shew, B. B., Stalker, H. T., Isleib, T. G., Sidahmed, R., and Beute, M. K. 1994. Effect of temperature on stability of components of resistance to Cercospora arachidicola in peanut. Phytopathology 84:10371043 .

53. Walker, A. K., and Schmitthenner, A. F. 1984. Heritability of tolerance to Phytophthora rot in soybean. Crop Sci. 24:490-491.

54. Ward, E. W. B., Cahill, D. M., and Bhattacharyya, M. K. 1989. Early cytological differences between compatible and incompatible interactions of soybeans with Phytophthora megasperma f.sp. glycinea. Physiol. Mol. Plant P. 34:264-283.

55. Ward, E. W. B., Stössel, P., and Lazarovitz, G. 1981. Similarities between age-related and race-specific resistance of soybean hypocotyls to Phytophthora megasperma var. sojae. Phytopathology 71:504-508.

56. Wrather, J. A., Anderson, T. R., Arsyad, D. M., Gai, J., Ploper, L. D., Porta-Puglia, A., Ram, H. H., and Yorinori, J. T. 1997. Soybean disease loss estimates for the top 10 soybean producing countries in 1994. Plant Dis. 81:107-110.

57. Wrather, J. A., Koenning, S. R., and Anderson, T. R. 2003. Effect of diseases on soybean yields in the United States and Ontario (1999 to 2002). Plant Health Progr. Online publication no. 10.1094/PHP-2003$0325001 \mathrm{RV}$.

58. Wrather, J. A., Stienstra, W. C., and Koenning, S. R. 2001. Soybean disease loss estimates for the United States from 1996 to 1998. Can. J. Plant Pathol. 23:122-131.

59. Xue, A. G., and Davidson, C. G. 1998. Components of partial resistance to black spot disease (Diplocarpon rosae Wolf) in garden roses. Hort. Sci. 33:96-99.

60. Young, B. A., St. Martin, S. K., Schmitthenner, A. F., Buzzell, R. I., and McBlain, B. A. 1994. Absence of residual effects of defeated resistance genes of Phytophthora rot of soybean. Crop Sci. 34:409-414. 